\title{
EHMTI-0317. Transcranial direct current stimulation in chronic migraine: a pilot trial combining cathodal visual and anodal dlpfc stimulation
}

\author{
R Baschi", SL Sava, V La Salvia, V De Pasqua, J Schoenen, D Magis \\ From 4th European Headache and Migraine Trust International Congress: EHMTIC 2014 \\ Copenhagen, Denmark. 18-21 September 2014
}

\section{Background}

Contrary to episodic migraine, chronic migraine $(\mathrm{CM})$ is associated with sensitisation of visual cortex and depression that is characterized by left DLPFC hypoactivity. Transcranial direct current stimulation (tDCS) is able to activate (anode) or inhibit (cathode) the underlying cortex,thus of potential therapeutic interest in CM.

\section{Aim}

To explore the effect in CM of simultaneous tDCS over the visual cortex and IDLPFC with a novel tDCS Cefaly ${ }^{\circ}$ device.

\section{Method}

We recruited 20 patients suffering from chronic migraine $(\mathrm{n}=15)$ or medication overuse headache $(\mathrm{n}=5)$ (ICHD-III beta 1.3 or 8.2).All had stable preventive treatment for at least 2 months. We applied anodal tDCS over F3 and cathodal over Oz: intensity $2 \mathrm{~mA}$, duration 20min, daily for 8 weeks. Patients filled in headache diaries before (T0), during (T1) and after treatment (T2).We recorded CHEPS, QST, nBR and VEP at baseline (T0), immediately after (T1) and after 8 weeks (T2).

\section{Results}

Total headache days decreased from $21.9 /$ month at T0 to $15.7 /$ month at T2 $(-28.4 \%, \mathrm{p}=0.004)$. Severe migraine attacks were reduced by $43.7 \%(\mathrm{p}=0.05)$, headache hours by $30.2 \%(\mathrm{p}=0.02)$. The $50 \%$ responder rate for migraine days was $33.3 \%$.There was no significant therapeutic effect in $\mathrm{MOH}$ patients.
tDCS had no effect on VEP and QST. It increased $\mathrm{nBR}$ habituation at $\mathrm{T} 1(\mathrm{p}=0.05)$ but decreased habituation of frontal CHEPS at T2 $(\mathrm{p}=.04)$ in CM.

\section{Conclusion}

These results suggests that tDCS inhibiting the visual cortex while activating IDLPFC has an interesting therapeutic potential in chronic migraineurs. A sham-controlled trial seems worthwhile.

No conflict of interest.

Published: 18 September 2014

doi:10.1186/1129-2377-15-S1-G4

Cite this article as: Baschi et al:: EHMTI-0317. Transcranial direct current stimulation in chronic migraine: a pilot trial combining cathodal visual and anodal dlpfc stimulation. The Journal of Headache and Pain 201415 (Suppl 1):G4

Submit your manuscript to a SpringerOpen ${ }^{\odot}$ journal and benefit from:

- Convenient online submission

- Rigorous peer review

- Immediate publication on acceptance

- Open access: articles freely available online

- High visibility within the field

- Retaining the copyright to your article

Submit your next manuscript at $>$ springeropen.com

Department of Neurology, CHR Citadelle, Liege, Belgium

C 2014 Baschi et al; licensee Springer. This is an Open Access article distributed under the terms of the Creative Commons Attribution License (http://creativecommons.org/licenses/by/2.0), which permits unrestricted use, distribution, and reproduction in any medium, provided the original work is properly cited. 